\title{
Bioanalysis
}

\section{Recommendations on incurred sample stability (ISS) by GCC}

The topic of incurred sample stability (ISS) has generated considerable discussion within the bioanalytical community in recent years. The subject was an integral part of the seventh annual Workshop on Recent Issues in Bioanalysis (WRIB) held in Long Beach, CA, USA, in April 2013, and at the Global CRO Council for Bioanalysis (GCC) meeting preceding it. Discussion at both events focused on the use of incurred samples for ISS purposes in light of results from a recent GCC survey completed by member companies. This paper reports the consensus resulting from these discussions and serves as a useful reference for depicting ISS issues and concerns, summarizing the GCC survey results and providing helpful recommendations on ISS in the context of bioanalytical method development and application.

Steve Lowes', Richard LeLacheur ${ }^{2}$, Ronald Shoup ${ }^{3}$, Fabio Garofolo ${ }^{4}$,

Isabelle Dumont ${ }^{4}$, Suzanne Martinez ${ }^{4}$, Jennifer Zimmer ${ }^{5}$, Maria Cruz Caturla ${ }^{6}$, Philippe Couerbe ${ }^{7}$, Kayode Awaiye ${ }^{8}$, Saadya Fatmi ${ }^{9}$, Raymond Farmen ${ }^{10}$, Curtis Sheldon ${ }^{10}$, Joseph Bower ${ }^{11}$, Michele Fiscella ${ }^{11}$, Douglas Fast ${ }^{12}$, Stephanie Cape ${ }^{12}$, Jim Hulse ${ }^{t, 13}$, John Kamerud ${ }^{\dagger}, 13$, Tee Zhang $^{14}$, Stephanie Pasas-Farmer ${ }^{15}$,

Wei Garofolo*,16, Marc Moussallie ${ }^{17}$, Mario Rocci'18, John Allinson ${ }^{\ddagger 19}$, Dominique Gouty ${ }^{\S, 20}$, Mike Buonarati ${ }^{21}$, Nadine Boudreau ${ }^{22}$, Brigitte Pellerin ${ }^{22}$, Jenny Lin ${ }^{23}$, Allan $\mathrm{Xu}^{24}$, Roger Hayes ${ }^{25}$, Mohammed Bouhajib ${ }^{26}$, Mary Stipancic ${ }^{26}$, Robert Nicholson ${ }^{27}$, Corey Nehls ${ }^{28}$, Mark Warren ${ }^{29}$, Shane Karnik ${ }^{30}$, Richard Houghton ${ }^{\ddagger}, 31$, Craig Stovold ${ }^{\ddagger}, 31$, Scott Reuschel ${ }^{32}$, Laura Cojocaru ${ }^{33}$, John Marcelletti ${ }^{34}$, Xinping Fang $^{35}$, Ian Smith ${ }^{36}$ \& Andrea Watson ${ }^{36}$

Note: Except for the first author who provided a major contribution, all authors are presented in alphabetical order by company affiliation.

*Author for correspondence: Tel.: +1 514236 4225; Fax: +1 450505 1406; wei@global-cro-council.org

Author affiliations can be found at the end of this article.
The Global CRO Council for Bioanalysis (GCC) represents an independent international consortium bringing together many senior-level CRO representatives to discuss and share ideas on scientific and regulatory issues specific to the bioanalytical field. Since its formation in 2010 [1], the GCC meets regularly to discuss various topics and challenges unique to the outsourcing industry [2-4]. The GCC has also published several influential White Papers sharing recommendations on issues important to the bioanalytical community [5-9].
The re-assay of study samples as part of incurred sample reanalysis (ISR) to evaluate the reproducibility of bioanalytical results from incurred samples is an established and routine practice in regulated bioanalysis and expected by most regulatory authorities worldwide. ISR is a regulatory requirement included in the EMA guideline on bioanalytical method validation [10] and part of the new draft US FDA guidance on bioanalytical method validation issued in September 2013 [11]. However, because reanalysis introduces a time period between

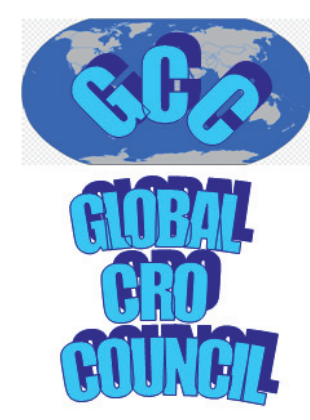

FUTURE
SCIENCE part of 
initial and subsequent results, the typical ISR experiment raises questions of analyte stability, as well as assay reproducibility over time. GCC members have reported examples of ISR failure resulting from issues of analyte stability or related metabolites unique to incurred study samples [12-14]. These findings have prompted further discussion on the value of conducting stability assessments with incurred samples and the effectiveness of established ISR experiment guidelines.

To date, conversations about incurred sample stability (ISS) have focused primarily on bioanalytical methods using liquid chromatography-mass spectrometry (LC-MS) and not ligand-binding assays (LBA) because ISR failure can be discrete between LC-MS and LBA due to differences in experimental design and execution. Also, proteins present biotransformation scenarios fundamentally different from those of small molecules, thereby decreasing the likelihood of biotransformation being a root cause for ISS issues with biological molecules. While the global bioanalytical community acknowledges the limitations of ISS in practical LC-MS bioanalysis, it maintains sufficient interest in the subject to include ISS as a topic at recent international forums and conferences on bioanalysis. Discussion on ISS was initiated at the sixth Workshop on Recent Issues in Bioanalysis (WRIB) in 2012 [15], and continued more extensively at the seventh WRIB in 2013 [16].

\section{Key terms}

Incurred sample reanalysis (ISR): A repeated

measurement of analyte concentration from a portion of incurred samples to demonstrate reproducibility of the analytical results.

Incurred sample stability (ISS): Reanalysis of a portion of incurred samples over a given period of time to determine whether the analyte is stable and analyte concentrations are reproducible.

Liquid chromatography-mass spectrometry (LC-MS): Laboratory technique in which molecules are separated in the liquid phase and then ionized and analyzed in the gas phase. The $\mathrm{m} / \mathrm{z}$ of the intact molecules is measured, as are fragments of the molecule after it has been fragmented within the MS system.

Ligand-binding assay (LBA): Laboratory technique that makes use of the binding between a ligand and specific binding reagents (e.g., binding of an antigen to specific antibodies) in order to quantify the specific ligand in a sample.

Biotransformation: Series of chemical modifications made by an organism on a chemical compound (e.g., by enzymatic activity). The metabolism of a compound in a body is an example of a biotransformation.

\section{ISS considerations}

ISS refers to the repeat analysis of one or several incurred samples after an extended period of time to demonstrate analyte concentration stability in study samples over that time. In general, the established method to assess analyte stability is to use spiked quality control (QC) samples of known concentration. There are some instances, however, where QC samples do not adequately represent incurred samples, for example in cases where the presence of other components in samples generated in vivo significantly impact the quantified analyte. A common scenario leading to reproducibility issues is when an incurred sample contains a conjugated metabolite that back-converts to the parent analyte. Interference from other stability events (e.g., impact of hemolysis on stability or change in free/total drug ratio if not stabilized at sample collection) particular to incurred study samples (as opposed to analyte-spiked control matrix QCs) is another potential issue. In these cases, the use of incurred samples for stability assessment in-matrix may be relevant and scientifically justified as part of bioanalytical method development and application to sample analysis.

As part of an initiative to investigate ISS practices within the CRO industry, the GCC sent member companies a survey on the use of incurred samples for bioanalytical method development and validation. A section of this survey was specific to the use of incurred samples for stability investigations, asking each company to share its approach to ISS. The main goal of this survey was to facilitate discussion on the value and practicality of experiment design when conducting an ISS assessment. Dr Steve Lowes (Vice President Scientific, Quintiles Bioanalytical and ADME Labs) presented the survey results at the seventh GCC Closed Forum held in Long Beach, CA, USA on April 8, 2013, and at the seventh WRIB meeting succeeding it.

\section{Summary of survey data}

Over 30 CROs responded to the GCC survey on ISS. The questions and responses are presented in Table 1.

\section{Discussion}

The GCC survey covered several aspects of ISS practices and the results provided an effective platform for discussing critical elements of the topic at subsequent GCC meetings. General consensus from these discussions was that most laboratories have encountered stability issues unique to in vivo-generated study samples, but that these events were relatively infrequent. Meeting participants agreed to maintain the standard practice of analyte-spiked stability QCs 
Table 1. Global CRO Council for Bioanalysis survey on incurred sample stability.

\begin{tabular}{|c|c|}
\hline Question & Answer ${ }^{\dagger}$ \\
\hline $\begin{array}{l}\text { How do you believe incurred study samples } \\
\text { should be used to support ISR? }\end{array}$ & $\begin{array}{l}\text { - Per current practice: } 14 \% \\
\text { - Extended to include true ISS experiments: } 26 \% \\
\text { - For additional ISR failure investigation experiments: } 43 \% \\
\text { - Other: } 17 \%\end{array}$ \\
\hline $\begin{array}{l}\text { If you suggested additional stability } \\
\text { experiments with incurred samples, what } \\
\text { do you suggest using? }\end{array}$ & $\begin{array}{l}\text { - Standard addition to incurred samples (a): } 0 \% \\
\text { - Using only existing analyte concentration in incurred } \\
\text { samples (b): } 34 \% \\
\text { - Flexibility to use (a) or (b): } 51 \% \\
\text { - Other: } 14 \%\end{array}$ \\
\hline $\begin{array}{l}\text { Have you performed ISS? If yes, in which } \\
\text { situations? }\end{array}$ & $\begin{array}{l}\text { - Back-conversion of unknown conjugates: nine responses } \\
\text { - Acyl-glucuronides and their metabolites: five responses } \\
\text { - Enzymatic degradation of analytes: three responses } \\
\text { - Major matrix instability: five responses } \\
\text { - Inability to support stability with QCs: five responses } \\
\text { - Oncology studies for co-admin stability: three responses } \\
\text { - Other: four responses }\end{array}$ \\
\hline How often do you perform ISS? & $\begin{array}{l}\text { - Never: } 40 \% \\
\text { - Occasionally as needed/directed: } 46 \% \\
\text { - Always: } 3 \%\end{array}$ \\
\hline Do you think ISS should be a regulation? & $\begin{array}{l}\text { - Yes: } 3 \% \\
\text { - Only a recommendation to be used on case-by-case } \\
\text { basis: } 63 \% \\
\text { - No: } 20 \%\end{array}$ \\
\hline $\begin{array}{l}\text { If you perform ISS, for which stabilities do } \\
\text { you perform it? }\end{array}$ & $\begin{array}{l}\text { - Freeze-thaw stability: } 13 \text { responses } \\
\text { - Bench-top (ambient) stability: } 12 \text { responses } \\
\text { - Frozen sample stability: } 17 \text { responses }\end{array}$ \\
\hline $\begin{array}{l}\text { If you perform ISS experiments, what do } \\
\text { you use? }\end{array}$ & $\begin{array}{l}\text { - Pooled samples (a): three responses } \\
\text { - Individual samples as in ISR (b): five responses } \\
\text { - Flexibility to use (a) or (b) dependent on the study and/or } \\
\text { sample volume: } 11 \text { responses }\end{array}$ \\
\hline $\begin{array}{l}\text { If you perform ISS experiments, which } \\
\text { acceptance criteria do you apply? }\end{array}$ & $\begin{array}{l}\text { - Same as ISR: } 40 \% \\
\text { - Wider than ISR due to stability issues: } 9 \% \\
\text { - Other: } 51 \%\end{array}$ \\
\hline Have you officially implemented ISS? & $\begin{array}{l}\text { - Yes with SOP on ISS: } 30 \% \\
\text { - Only in method development: } 0 \% \\
\text { - Only in specific cases beyond scope of current SOP: } 29 \% \\
\text { - No: } 54 \%\end{array}$ \\
\hline How do you calculate time zero in ISS? & $\begin{array}{l}\text { - Fresh: collecting and analyzing samples fresh ( } 2 \mathrm{~h} \text { from } \\
\text { collection): } 6 \% \\
\text { - Frozen: at first freeze-thaw cycle just after collection: } 26 \% \\
\text { - Estimated: } 14 \% \\
\text { - Other: } 54 \%\end{array}$ \\
\hline
\end{tabular}

${ }^{\dagger}$ Responses were calculated as a percentage of survey respondents marking individual multichoice answer on the survey. For some questions, respondents marked as many individual multichoice answers as were applicable; consequently, total percentage for each question does not always equal $100 \%$.

ISR: Incurred sample reanalysis; ISS: Incurred sample stability; SOP: Standard operating procedure.

along with the required ISR experiment to indicate whether further ISS investigations were warranted.

A central topic of discussion at the meeting was the presence of unstable metabolites of the drug of interest in incurred samples. Appropriate steps can be taken in bioanalytical method development to stabilize metabolites that can manifest as ISS anomalous events. Participants acknowledged that other matrix stability events can theoretically introduce interference and subsequent inaccuracies in analyte measurement, and 
Box 1. The Global CRO Council for Bioanalysis recommendation on when to conduct incurred sample stability experiments.

The Global CRO Council for Bioanalysis (GCC) recommends that incurred sample stability (ISS) experiments should not be conducted routinely, but on a case-by-case basis when specific analyte stability issues are suspected in incurred samples. The typical use of known quality control samples to assess analyte stability in matrix is considered adequate in most cases; however, specific issues may be introduced by in vivo drug metabolism, metabolite back-conversion, enzymatic degradation of analyte, etc. In addition, ISS experiments could serve as a useful investigational tool in the context of incurred sample reanalysis failures or unexpected trends, as stability issues in incurred samples may potentially be involved. Because it is appropriate to conduct ISS only in specific situations when scientifically justified, the GCC recommends that ISS should not be formally included as part of global regulatory requirements.

agreed that the appropriate ISR experiment would call attention to these problems and lead to ISS being part of any investigational follow-up.

Another topic of debate was the difficulty of defining a time-zero analyte concentration in incurred samples. This discussion raised the question: 'what is the analyte concentration at the time of sample collection?' The GCC survey and following discussion highlighted a range of approaches to this problem. The most popular strategy was, as with ISR, using a previously measured concentration following frozen sample storage (i.e., the first verifiable result from a stored study sample). It was acknowledged, however, that in cases where the time period between two successive measurements is too short, analyte instability may be missed. This issue led to a discussion about the ISR experiment inherently being a combination of assay reproducibility and analyte stability testing, and the conclusion that if the ISR experiment is expected to raise attention to potential ISS problems, then sufficient time between the initial and ISR analyses needs to be built into the ISR program. Participants agreed that when ISS is a concern, short-term (bench-top), freeze-thaw and if necessary, long-term frozen storage stability should be investigated. Beyond these fundamental experimental design considerations, it was noted that individual laboratories may have specific ISS investigational strategies not discussed at the GCC meeting.

Overall, the survey and the GCC discussion that followed suggest that some of the bioanalytical community believes that ISS assessment, in addition to the ISR experiment, has value in certain circumstances. The results of the survey indicate that most respondents do not routinely conduct ISS experiments but perform them on a case-by-case basis when it may help address particular situations. The need to conduct ISS experiments seems to emerge particularly in the context of ISR failure investigations, where the failure can be attributed to analyte instability in incurred samples.

\section{Recommendations}

Following the results of the GCC survey and the subsequent discussions at the April 2013 GCC Closed Forum, the GCC came forward with its recommendations on ISS. As stated earlier, discussions on the topic focused on LC-MS bioanalysis and therefore must be considered in the context of these recommendations, which are intended to help the industry make thoughtful decisions toward implementing and conducting ISS procedures. More specifically, the following recommendations address when ISS experiments should occur during regulated LC-MS bioanalysis and how they should be conducted.

The GCC recommendation on when to conduct ISS experiments is shown in Box 1.

The GCC recommendation on how to conduct ISS experiments is shown in Box 2.

\section{Future perspective}

The GCC will continue to provide recommendations on bioanalytical topics of global interest and expand its membership by coordinating its activities with regional

Box 2. The Global CRO Council for Bioanalysis recommendation on how to conduct incurred sample stability experiments.

The Global CRO Council for Bioanalysis (GCC) recommends that when an incurred sample stability experiment is deemed necessary, the experimental approach should take into account the existing information available on the analyte under study. No standardized practice is recommended, as the approach is to be determined case-by-case using sound scientific judgment. Because it is difficult to obtain true time-zero concentration values in incurred samples (i.e., immediately following sample collection), it is more practical to use the first verifiable measurement of the sample. This would allow an evaluation of relative stability. Incurred sample stability could include the assessment of short-term (bench top), freeze-thaw and/or long-term freezer stability, depending on the extent of information needed. 
and international meetings held by the pharmaceutical industry. Please contact the GCC [17] for the exact date and time of future meetings, and for membership information.

\section{Acknowledgements}

The GCC would like to thank the following: S Lowes (Quintiles Bioanalytical and ADME Labs) for leading this initiative within GCC, designing the survey, collating the results and facilitating the discussion during the seventh GCC meeting (Long Beach, CA, USA). I Dumont and S Martinez (Algorithme Pharma) for writing the first draft of this White Paper. The GCC member companies who answered the survey. The GCC member representatives who have sent comments and suggestions to complete this White Paper. K Henion (Kathryn Henion Communications) for final editing of this White Paper. W Garofolo (GCC) for organizing the logistics of the meetings and coordinating the review of this White Paper.

\section{Financial \& competing interests disclosure}

The authors have no relevant affiliations or financial involvement with any organization or entity with a financial interest in or financial conflict with the subject matter or materials discussed in the manuscript. This includes employment, consultancies, honoraria, stock ownership or options, expert testimony, grants or patents received or pending or royalties.

No writing assistance was utilized in the production of this manuscript.

\section{Author affiliations}

Except for the first, company names are in alphabetical order:

'Quintiles Bioanalytical \& ADME Labs, Ithaca, NY, USA

${ }^{2}$ Agilux Laboratories, Worcester, MA, USA

${ }^{3}$ AIT Bioscience, Indianapolis, IN, USA

${ }^{4}$ Algorithme Pharma, Laval, Quebec, Canada

${ }^{5}$ Alturas Analytics, Moscow, ID, USA

${ }^{6}$ Anapharm Europe, Barcelona, Spain

${ }^{7}$ Atlanbio, Saint-Nazaire, France

${ }^{8}$ BioPharma Services, Toronto, Ontario, Canada

${ }^{9}$ Biotrial Bioanalytical Services, Laval, Quebec, Canada

${ }^{10}$ Celerion, Lincoln, NE, USA

"Covance Laboratories, Chantilly, VA, USA

${ }^{12}$ Covance Laboratories, Madison, WI, USA

${ }^{13}$ EMD Millipore, St Charles, MO, USA

${ }^{14}$ Frontage Laboratories, Shanghai, China

${ }^{15}$ Frontage Laboratories, Exton, PA, USA

${ }^{16} \mathrm{Global}$ CRO Council for Bioanalysis (GCC), 15 Sunview Drive, Toronto, Ontario, L4H 1Y3, Canada

${ }^{17} \mathrm{HLS}$, Somerset, NJ, USA

${ }^{18}$ ICON Laboratories, Whitesboro, NY, USA

\section{References}

1 Premkumar N, Lowes S, Jersey J et al. Formation of a Global Contract Research Organization Council for Bioanalysis. Bioanalysis 2(11), 1797-1800 (2010).

2 Breda N, Garofolo F, Cruz Caturla M et al. The 3rd Global CRO Council for Bioanalysis at the International Reid Bioanalytical Forum. Bioanalysis 3(24), 2721-2727 (2011).

3 Lowes S, Jersey J, Shoup R et al. 4th Global CRO Council for Bioanalysis: coadministered drugs stability, EMA/US FDA Guidelines, 483s and Carryover. Bioanalysis 4(7), 763-768 (2012).

4 Nicholson R, Lowes S, Caturla MC et al. 6th GCC focus on LBA: critical reagents, positive controls and reference standards; specificity for endogenous compounds; biomarkers; biosimilars. Bioanalysis 4(19), 2335-2342 (2012).

5 Lowes S, Jersey J, Shoup R et al. Recommendations on: internal standard criteria; stability; incurred sample reanalysis and recent 483 s by the Global CRO Council for Bioanalysis. Bioanalysis 3(12), 1323-1332 (2011).

${ }^{19}$ ICON Laboratories, Manchester, UK

${ }^{20}$ Intertek, San Diego, CA, USA

${ }^{21}$ Intertek, El Dorado Hills, CA, USA

${ }^{22}$ InVentiv Health Clinical, Quebec City, Quebec, Canada

${ }^{23} \mathrm{JCL}$ Bioassay USA, Hoffman Estates, IL, USA

${ }^{24}$ Keystone Bioanalytical, North Wales, PA, USA

${ }^{25} \mathrm{MPI}$ Research, Mattawan, MI, USA

${ }^{26}$ Pharma Medica Research, Mississauga, Ontario, Canada

${ }^{27} \mathrm{PPD}$, Richmond, VA, USA

${ }^{28} \mathrm{PPD}$, Middleton, WI, USA

${ }^{29}$ PRA International, Lenexa, KS, USA

${ }^{30}$ Pyxant Labs, Colorado Springs, CO, USA

${ }^{31}$ Quotient Bioresearch, Fordham, UK

${ }^{32}$ Tandem Labs, Salt Lake City, UT, USA

${ }^{33}$ Tandem Labs, West Trenton, NJ, USA

${ }^{34}$ Tandem Labs, San Diego, CA, USA

${ }^{35}$ XenoBiotic Laboratories, Plainsboro, NJ, USA

${ }^{36}$ York Bioanalytical Solutions, York, UK

${ }^{+}$Current address: Eurofins Bioanalytical Services, St Charles, MO, USA

*Current address: LGC, Fordham, UK

${ }^{\S}$ Current address: BioAgilytix, Durham, NC, USA

6 Boterman M, Doig M, Breda M et al. Recommendations on the interpretation of the new EMA Guideline on Bioanalytical Method Validation by Global CRO Council for Bioanalysis (GCC). Bioanalysis 4(6), 651-660 (2012).

7 Sangster T, Maltas J, Struwe P et al. Recommendations on ISR in multi-analyte assays, QA/bioanalytical consultants and GCP by Global CRO Council for Bioanalysis (GCC). Bioanalysis 4(14), 1723-1730 (2012).

8 Lowes S, Boterman M, Doig M et al. Recommendations on bioanalytical method stability implications of coadministered and co-formulated drugs by Global CRO Council for Bioanalysis (GCC). Bioanalysis 4(17), 2117-2126 (2012).

9 Houghton R, Gouty D, Allinson J et al. Recommendations on biomarker bioanalytical method validation by GCC. Bioanalysis 4(20), 2439-2446 (2012).

10 European Medicines Agency, Committee for Medicinal Products for Human Use (CHMP). Guideline on Bioanalytical Method Validation. London, UK (2011). 
11 US FDA. Draft Guidance for Industry: Bioanalytical Method Validation. US Department of Health and Human Services, US FDA. Center for Drug Evaluation and Research, Silver Spring, MD, USA (2013).

12 Rocci ML Jr, Collins E, Wagner-Caruso KE et al. Investigation and resolution of incurred sample reanalysis failures - two case studies. Bioanalysis 3(9), 993-1000 (2011).

13 Voicu V, Gheorghe MC, Sora ID et al. Incurred sample reanalysis: different evaluation approaches on data obtained for spironolactone and its active metabolite canrenone. Bioanalysis 3(12), 1343-1356 (2011).

14 Yuan L, Jian W, Zhang D et al. Application of a stabilizer cocktail of $N$-ethylmaleimide and phenylmethanesulfonyl fluoride to concurrently stabilize the disulfide and ester containing compounds in a plasma LC-MS/MS assay. J. Pharm. Biomed. Anal. 88, 552-561 (2014).

15 DeSilva B, Garofolo F, Rocci M et al. 2012 White Paper on recent issues in bioanalysis and alignment of multiple guidelines. Bioanalysis 4(18), 2213-2226 (2012).

16 Stevenson L, Rocci M, Garofolo F et al. 2013 White Paper on recent issues in bioanalysis: 'Hybrid' - the best of LBA and LCMS. Bioanalysis 5(23), 2903-2918 (2013).

17 Global CRO Council for Bioanalysis. www.global-cro-council.org 